\title{
A prospective, open label, clinical study for evaluation of management of chronic non-healing, non-diabetic leg ulcers in a tertiary care hospital
}

\author{
Sujoy Mukherjee ${ }^{1}$, Mohd. Arshad Raza ${ }^{1}$, Shobha Mukherjee $^{2}$, Piyush Bansal $^{3}$, Gaurav Joshi $^{4}$
}

\author{
${ }^{1}$ Department of Surgery, Rohilkhand Medical College, Bareilly, U.P., India \\ ${ }^{2}$ Department of Obstetrics \& Gynaecology, Rohilkhand Medical College, Bareilly, U.P., India \\ ${ }^{3}$ Department of General Surgery, Rohilkhand Medical College, Bareilly, U.P., India \\ ${ }^{4}$ MBBS Student, MLN Medical College, Allahabad, U.P., India
}

Received: 27 July 2015

Accepted: 19 August 2015

\author{
*Correspondence: \\ Dr. Sujoy Mukherjee, \\ E-mail: dr_joy22001@yahoo.com
}

Copyright: () the author(s), publisher and licensee Medip Academy. This is an open-access article distributed under the terms of the Creative Commons Attribution Non-Commercial License, which permits unrestricted non-commercial use, distribution, and reproduction in any medium, provided the original work is properly cited.

\begin{abstract}
Background: Accurate diagnosis is essential if patients with chronic leg ulceration are to receive optimal treatment. Multiple disciplinary approach is usually required for complete healing of chronic ulcers.

Methods: A prospective study of seven months duration was conducted on 50 consecutively admitted cases of chronic leg and foot ulcers in age group of 5-80 years of both genders. A through detailed history and clinical examination was undertaken. Local Symptoms, trophic skin changes and venous insufficiency if any was recorded. Both general and specific treatments were provided.

Results: Maximum cases were in the age group of 31-50 years, M: F ratio 1.9:1 and rural: urban ratio 2.57:1. Majority of patients were illiterate (76\%), and were drawn from lower class of the society (56\%). Majority of patients $(54 \%)$ were smokers, tobacco chewers or alcoholics. Site of ulcer was foot $52 \%$ followed by leg $18 \%$, ulcer origin was traumatic in $72 \%$ of cases and ischaemic ulcers were minimum $2 \%$. Symptom wise wound, pain and discharge $32 \%$ followed by wound and discharge $26 \%$ were noted. $66 \%$ of ulcers were secondarily infected and maximum number of cases $68 \%$ stayed in hospital for about 2 weeks. In $68 \%$ cases healing was complete in about 3 months.

Conclusions: A correct diagnosis, multidisciplinary approach, optimal treatment and assessment of vascular status can facilitate healing of chronic leg ulcers in nondiabetic cases.
\end{abstract}

Keywords: Leg ulcer, Non-healing, Non-diabetic

\section{INTRODUCTION}

Chronic non-healing ulcers of leg and foot represent a common problem causing great mental and physical agony and these patients do occupy considerable space in surgical wards. Further, these ghastly looking ulcers often emitting offensive smell pose difficult problem of daily dressing for the attending surgeon and misery to patients as well as burden to the community both in terms of finance and work loss. These ulcers involve a wide variety of spectrum of etiology, pathology, severity with significant morbidity and mortality. Thus, chronic perforating mutilating ulcers of leprosy and other sensory neuropathies, malignant ulcers and ulcers of professional beggars need special mention. Both specific ulcers like diabetic, tubercular or syphilitic ulcers, and non-specific ulcers do cause a lot of suffering and morbidity. In normal wound healing, the matrix metalloproteinases (MMPs) seems to be involved in various processes. ${ }^{1}$ In chronic non-healing lower extremity ulcers, healing generally does not progress in normal pathway and involve a series of complex events. ${ }^{2}$ 
The leg ulcer is the manifestation of an underlying problem that requires a clear diagnosis. Ulcers of leg and foot owing to variety of etiologies and underlying systemic diseases constitute a good bulk of patients. Moreover, leg ulcers significantly interfere with patient's lifestyles, involve considerable loss of work hours, enormous health care costs and reduced leisure activities.

The management of chronic non healing ulcers involve a lot of experimentation starting from such apparently ridiculous practice like application of mud, cow dung, various herbal preparations, down to antibiotics and antiseptics, vasodilators, antiplatelet rheologic agents and thrombolytic drugs, besides various other radiological interventional procedures like Percutaneous Transluminal Angioplasty (PTA) etc., with varying degree of success.

In the light of above noted facts, the present study is being carried out to analyze various presentations and incidence of ulcers over the leg and foot other than diabetes, their etiologies and to formulate a plan of management for best results. Besides, an attempt has also been made to identify the risk factors and high risk patients as well as difficulties encountered in the diagnosis.

\section{METHODS}

A prospective, open label clinical study of seven months duration (Jan 2015 - July 2015) was conducted at Rohilkhand Medical College and Hospital, Bareilly, U.P. The approval of study protocol was obtained from institutional ethical committee. Each patient participating in the clinical trial signed an informed consent form though one could withdraw without any prejudice at any time.

50 consecutively admitted cases of chronic leg and foot ulcers in the age group of 5 to 80 years of both genders were enrolled. Chronic non healing ulcer has been characterized as one which did not heal over a span of 6 weeks duration.

In all cases a detailed history was taken and they were subjected to through clinical examination. Sociodemographic data such as name, age, sex, occupation, educational status, socio-economic status, date of admission and discharge were noted down. Besides, history of trauma, thorn prick, shoe pressure, shoe bite and history of burn or complication of chemicals and herbal medications were also asked for. History of diabetes, ischemic heart disease, other chronic systemic ailments, smoking, alcohol drinking was asked and recorded. Diabetic patients were excluded from the study.

The site, depth and duration of ulcers were recorded and any previous ulceration noted. Local symptoms such as swelling, redness, discoloration, condition of non-healing wound, pain, discharge, were looked for and recorded. Trophic changes in skin, nails, muscles, hair were also recorded. Pathological lesions of foot like cellulitis, abscess, gangrene, foot deformity and their site were also looked for. Evidence of any precipitating factors like defective foot wear, cracks and cellulitis were noted.

All enrolled patients were thoroughly clinically examined for any chronic systemic ailment. Vascular insufficiency in lower limbs was detected by observing colour of limb (normal, pale, blue, black, purplish), condition of hair, nails muscle wasting and temperature. Pulsation of dorsalis pedis, posterior tibial, popliteal and femoral arteries were noted for presence or absence of pulsations, if pulsations were present volume was noted and compared with other limb pulsations. For neurological examination of lower limbs, sensations, reflexes and sweating were looked for to detect peripheral neuropathy.

In all patients $\mathrm{Hb} \%$, TLC, DLC, fasting or random blood sugar, blood urea and serum creatinine was routinely done. Urine was also examined routinely for both macroscopic and microscopic examination. Wherever vascular insufficiency was predicted in lower limbs, serum cholesterol/lipid profile was also done. In all ulcers, discharge was collected aseptically and sent to microbiology department for culture \& sensitivity. X-ray foot, leg and chest, and Doppler study was carried out, where indicated. Doppler ultrasound was done in 2 patients showing incompetence of long saphenous and calf perforators. Wasserman reaction and Kahn's test was performed where indicated ie: suspected syphilitic ulcers. In limited cases of non-healing ulcers, edge biopsy was done to assess the pathology of ulcers.

Following careful evaluation, patients were subjected to following line of management based on their general condition, type and severity of local lesion. The treatment consisted of treating any systemic condition that may impair/inhibit healing particularly malignant tumours, nutritional deficiencies of vitamins, iron, zinc and protein that could retard healing of ulcer. Additionally, elevation of limb when at rest and exercises with support bandages were also advised.

Debridement of ulcer was the most common surgical treatment for the enrolled patients since it helped in necrotic tissue removal, in assessing the depth of ulcer, its severity and also in controlling the infection.

Follow up of patients was done. In first 2 months 35 patients turned up for follow up, in next 4 months 15 patients came in and only 4 patients came for follow up at the end point (total 7 months).

\section{RESULTS}

Table 1 - shows demographic data of patients enrolled in the study. Patients in the age group of 31-50 years predominated (25/50 cases) followed by 51 to 70 years age. Only one case was noted below 10 year. Males predominated females. M:F ratio 1.9:1. Majority of 
patients were illiterate $76 \%(38 / 50)$ and only 2 patients were graduate. Larger number of patients were drawn from lower class of the society $56 \%$ (28/50). Majority of patients belong to rural populace. R:U ration 2.57:1. A great majority of patients were smokers, tobacco chewers, or alcoholics (54\%) (27/50).

Table 1: Socio-demographic data of chronic non-healing ulcers of leg and foot.

\begin{tabular}{|c|c|c|c|c|c|c|c|c|}
\hline $\begin{array}{l}\text { Age } \\
\text { (years) }\end{array}$ & $\begin{array}{l}\text { Male } \\
\text { No. }\end{array}$ & $\begin{array}{l}\text { Female } \\
\text { No. }\end{array}$ & Educational status & No. & $\begin{array}{l}\text { Socio-economic } \\
\text { class }\end{array}$ & No. & Habits/Habitat & No. \\
\hline 1 to 10 & 0 & 1 & \multirow{2}{*}{ Illiterate } & \multirow{2}{*}{38} & \multirow{2}{*}{ Lower class } & \multirow{2}{*}{28} & \multirow{2}{*}{ Smokers } & \multirow{2}{*}{8} \\
\hline 11 to 20 & 3 & 0 & & & & & & \\
\hline 21 to 30 & 4 & 0 & \multirow{2}{*}{ Less than high school } & \multirow{2}{*}{6} & \multirow{2}{*}{ Upper lower } & \multirow{2}{*}{11} & \multirow{2}{*}{ Tobacco, chewers } & \multirow{2}{*}{11} \\
\hline 31 to 40 & 7 & 6 & & & & & & \\
\hline 41 to 50 & 7 & 5 & \multirow{2}{*}{ Upto high school } & \multirow{2}{*}{4} & \multirow{2}{*}{ Lower middle } & \multirow{2}{*}{7} & Alcoholic & 8 \\
\hline 51 to 60 & 5 & 3 & & & & & Normal & 23 \\
\hline 61 to 70 & 5 & 2 & \multirow[t]{2}{*}{ Graduate } & \multirow[t]{2}{*}{2} & \multirow[t]{2}{*}{ Upper middle } & \multirow[t]{2}{*}{4} & $\begin{array}{l}\text { Habitat } \\
\text { Rural }\end{array}$ & 36 \\
\hline 71 to 80 & 2 & 0 & & & & & Urban & 14 \\
\hline Total & 33 & 17 & & 50 & & 50 & & 50 \\
\hline
\end{tabular}

Table 2 - shows distribution, type and characteristics of ulcers As well as associated systemic diseases. Chronic foot ulcers accounted for 26 (52\%) cases followed by 18 $(36 \%)$ cases of ulcers in leg region. $72 \%$ were traumatic ulcers, $14 \%$ trophic ulcers, $8 \%$ venous ulcer, $4 \%$ malignant ulcer and $2 \%$ ischaemic ulcer. As regards symptomatology $22 \%$ presented with a wound, $20 \%$ wound and pain, 26\% wound and discharge, and 32\% presented with wound, pain and discharge. Associated systemic diseases were leprosy in $12 \%$ cases, varicose vein in $6 \%$ and hypertension and malignancy each in $4 \%$ cases. Both tobacco chewing and smoking as well as excessive alcohol consumption were important risk factors. In the present study amputation of toes was done in 3 patients.

Table 2: Distribution of ulcers and their characteristics.

\begin{tabular}{|lcllllllll|}
\hline $\begin{array}{l}\text { Site of } \\
\text { ulcer }\end{array}$ & No. (\%) & $\begin{array}{l}\text { Type of } \\
\text { ulcer }\end{array}$ & No. (\%) & Symptomatology & No. $(\%)$ & Hb\% & No. (\%) $\begin{array}{l}\text { Associated } \\
\text { systemic } \\
\text { disease }\end{array}$ & $\begin{array}{l}\text { Cases } \\
\text { No. }(\%)\end{array}$ \\
\hline Foot & $26(52 \%)$ & $\begin{array}{l}\text { Traumatic } \\
\text { Trophic }\end{array}$ & $\begin{array}{l}36(72 \%) \\
7(14 \%)\end{array}$ & $\begin{array}{l}\text { Wound } \\
\text { Wound and pain }\end{array}$ & $\begin{array}{l}11(22 \%) \\
10(20 \%)\end{array}$ & $<8 \mathrm{~g} \%$ & $\begin{array}{l}10 \\
(20 \%)\end{array}$ & $\begin{array}{l}\text { Leprosy } \\
\text { Varicose vein }\end{array}$ & $\begin{array}{l}6(12 \%) \\
3(6 \%)\end{array}$ \\
\hline $\begin{array}{l}\text { Ankle } \\
\text { joint }\end{array}$ & $6(12 \%)$ & Venous & $4(8 \%)$ & $\begin{array}{l}\text { Wound and } \\
\text { discharge }\end{array}$ & $13(26 \%)$ & $8-10 \mathrm{~g} \%$ & $\begin{array}{l}28 \\
(56 \%)\end{array}$ & Malignant & $2(4 \%)$ \\
\hline Leg & $18(36 \%)$ & $\begin{array}{l}\text { Malignant } \\
\text { Ishcaemic }\end{array}$ & $\begin{array}{l}2(4 \%) \\
1(2 \%)\end{array}$ & $\begin{array}{l}\text { Wound, pain and } \\
\text { discharge }\end{array}$ & $16(32 \%)$ & $>10 \mathrm{~g} \%$ & $\begin{array}{l}12 \\
(24 \%)\end{array}$ & Hypertension & $2(4 \%)$ \\
\hline
\end{tabular}

Table 3 - Shows that $66 \%$ of lower extremity ulcers were secondarily infected whereas rest $34 \%$ wee non-infected. Culture and sensitivity showed greater involvement of gram positive microorganisms and most common microorganism was coagulase positive Staphylococci. In the present study a number of agents were used for dressing purposes. In almost all the cases more than one agent was used. Thus eusol was used in $14 \%$ cases, povidone iodine $(5 \% \mathrm{w} / \mathrm{v})$ solution in $96 \%$, Hydrogen peroxide $97 \%$, metronidazole in $20 \%$. With regard to $\mathrm{Hb} \%, 20 \%$ patients had hemoglobin less than $8 \mathrm{gm} \%$,
$56 \%$ cases had hemoglobin between 8-10 gm\% while $24 \%$ had above $10 \mathrm{gm} \%$.

A great majority of cases $86 \%$ were discharged in about 15 days time once their wounds showed healthy granulation tissues and signs of healing. Minimal stay was of 2 days. Complete healing of ulcers was noted in $68 \%$ cases in about 3 months, whereas $4 \%$ of cases took almost 9 months for healing and these cases also took a longer period of stay in the hospital. In the present study no complications and no mortality was observed except in duration 3 cases toes were amputated. 
Table 3: Shows nature of ulcer, dressing agent used, stay in hospital and duration complete healing.

\begin{tabular}{|c|c|c|c|c|c|c|c|}
\hline Nature of ulcer & No. $(\%)$ & $\begin{array}{l}\text { Dressing agent } \\
\text { used }\end{array}$ & $\%$ Used & $\begin{array}{l}\text { Stay in } \\
\text { hospital }\end{array}$ & No. $(\%)$ & $\begin{array}{l}\text { Complete } \\
\text { healing }\end{array}$ & No. $(\%)$ \\
\hline \multirow[b]{2}{*}{ Secondarily infected } & \multirow[b]{2}{*}{$33(66 \%)$} & Providone iodine & $96 \%$ & $\leq 1$ week & $19(38 \%)$ & $\leq 3$ months & $34(68 \%)$ \\
\hline & & $\begin{array}{l}\text { Hydrogen peroxide } \\
\text { Eusol }\end{array}$ & $\begin{array}{l}97 \% \\
14 \%\end{array}$ & $<2$ weeks & 24( & $<6$ months & $14(28 \%)$ \\
\hline Non infected & $17(34 \%)$ & $\begin{array}{l}\text { Metronidazole } \\
\text { Turpentine Oil }\end{array}$ & $\begin{array}{l}20 \% \\
8 \%\end{array}$ & $\leq 6$ weeks & $7(14 \%)$ & $\leq 9$ months & $2(4 \%)$ \\
\hline
\end{tabular}

\section{DISCUSSION}

Though leg and foot ulcers are a major and a common problem in modern health care yet in comparison to diabetic foot ulcers, there is a sparse literature in respect to non-diabetic chronic lower extremity ulcers. There are many causes of chronic non-healing ulcers and these include problems with blood supply or drainage, infection, nerve damage, excess pressure, cancer etc. The prevalence of leg ulcers is probably between $0.18 \%$ to $1 \%$ of the population and this may show an upward trend as the average age of population increases.

About $85 \%$ of leg and foot ulcers were over the age of 64 years, thus, elderly population was more involved. Strandness et al. ${ }^{3}$ observed that in non-amputation group, the average age of the nondiabetic patients 63 years whereas, Tassiopoulos et al. ${ }^{4}$ in their study on 1249 ulcerated limbs recorded mean age of patients 59 years (95\% CI: 54-63, range 14-93). In the present study maximum numbers of cases were observed in age group of 31-50 years and males (66\%) dominated females. Sundresh et al. $^{2}$ also noted similar observation in their study of chronic leg ulcers in non-diabetic patients. Majority of cases in present study were illiterate, belong to lower socio-economic class, and belonging to rural areas and were smokers/tobacco chewers/alcoholic, a comparable data on these aspects were not available in the literature. However, Ribu et al. $^{5}$ In their study observed that greatest difference between diabetic foot ulcer patients and general population (as control) were more of the foot ulcer patients were men, older, living alone, less well educated and not working.

The site of ulcer in majority of cases was foot followed by leg and large numbers of cases were of traumatic origin. The probable explanation for an increased incidence of foot ulcers was due to a larger population in our study belonged to rural habitat who worked bare footed hence an increased chances of trauma to foot and toes. In contrast to our observations regarding site of ulceration Baker et al. ${ }^{6}$ noted $90 \%$ of ulcer were present in gaiter area, $2 \%$ in foot and $8 \%$ in leg. A wide array of etiology has been involved in the lower extremity ulcers. Traditionally leg ulcers have been associated with venous insufficiency in $80-90 \%$ cases, $5-10 \%$ has an arterial origin. ${ }^{7}$ Chronic leg ulcers are commonly due to poor drainage of blood from the legs (venous insufficiency) and/or poor blood supply to the legs (peripheral vascular disease). Venous ulcers are usually associated with deep venous insufficiency. ${ }^{6}$ Chronic venous ulcers are more common in women. The etiological factor contributing chronic ulceration of leg is deep vein thrombosis in $96 \%$ of cases. Primary varicosity of the long saphenous system and/or short saphenous system is one of the causative factors for venous ulcerations. ${ }^{8}$ The sapheno femoral incompetence is the principal causative factor for venous ulceration $(94.4 \%) .{ }^{8}$ Older people particularly smokers may have narrowing of the blood vessels leading to decreased blood flow to the legs and feet. Further, minor trauma to the lower limbs can cause non-healing ulcer owing to poor blood supply. Rarely blood vessels can become inflamed as a part of an autoimmune disease and lead to chronic ulcers. Squamous cell carcinoma (Marjolin's ulcer) is the most common burn scar neoplasm though other neoplasm have also been reported. ${ }^{9}$

In our study majority of cases had ulcers for more than 10 weeks and were of traumatic origin. In variance to our observation concerning the etiology of ulcer, Sundresh et $\mathrm{al}^{2}{ }^{2}$ observed maximum cases of ulcer with venous pathology and malignancy. Strandness et al. ${ }^{3}$ conducted a study on 77 patients (42 diabetic and 35 nondiabetic) with complains involving lower extremity, presumably secondary to occlusive diseases of arterial system. The results of the combined clinical-pathological study of large and small arteries in the diabetics and nondiabetics patients showed that the diabetic patients had the same incidence of occlusion in the femoral-popliteal system but a higher incidence below the Knee ${ }^{3}$ Further, a specific lesion of small arteries and arterioles which distinguished the diabetics from nondiabetic was not observed. Besides, pulse categories were nearly the same and the plethysmographic studies indicated nearly the same pattern of occlusive involvement of the major arteries. ${ }^{3}$

In the present study detailed history and through systemic examination has revealed that the patients of chronic lower extremity ulcer owing to decreased mobility and state of depression, anxiety and irritability suffered from poor Health Related Quality-of-Life (HRQL). Obesity in these patients which significantly impaired mobility and work capacity is also associated with impaired HRQL. Ribu et al..$^{5}$ also observed that the patients of diabetic foot ulcers reported significantly poorer Health Related Quality-of-Life (HRQL) than diabetic population, 
moreover, these patients had significant lower HRQL than the general population on all scales. In patients of leg ulcers, reduction of swelling, pain and/or discharge may be important in improving quality-of-life.

With regard to symptomatology largest numbers of cases were of wound associated with pain and discharge followed by wound and discharge. Since there is sparse literature on lower extremity non-healing ulcers hence comparable data are lacking.

Nutritionally and in regard to anaemia larger number of patients had $\mathrm{Hb} \%$ ranging $8-10 \mathrm{gm} \%$ and were not well fed. Mechanick ${ }^{10}$ observed that nutritional metabolic support had direct applicability to wound healing. Comprehensive approach towards appropriate route for nutritional support, prioritizing nitrogen retention over energy balance in stressed patients, micronutrient supplementation are quite important. Armstrong et $\mathrm{al}^{11}$ in there study of 77 diabetic and 69 non-diabetic subjects with explored punctured wound of the feet observed that total lymphocyte count and hemoglobin, hematocrit, and albumin values were significantly lower in diabetics than in non-diabetics. In line with above observations, we also noted a decreased $\mathrm{Hb} \%$ in significant number of patients. In our study leprosy was present in $12 \%$, varicose vein in $6 \%$ hypertension and malignancy in $4 \%$ each as associated systemic ailments. Leprosy by damaging nerves leads to loss of sensation in hands and legs thereby proneness to trauma hence chronic leg ulcers.

Only after comprehensive assessment of patient to determine the diagnosis and etiology of ulcer, formulate an appropriate management plan. Adam et $\mathrm{al}^{12}$ in their study of 689 chronic leg ulcers observed that full clinical assessment, Ankle: Brachial Pressure Index (ABPI) and lower limb venous duplex scan were quite essential for clinching the diagnosis in $97 \%$ of chronic leg ulcers. Duplex in essential to confirm or exclude potentially correctable venous disease and allows tailored surgical intervention. Moreover duplex scanning is the best method for detecting venous reflex. Treatment must address oedema, infection and pressure. Managing peripheral oedema using compression bandages is often more important than topical dressing. ${ }^{13}$ Medical management apart from nutritional supplements and administration of broad spectrum antibiotics also involve weight reduction programs for patients with leg ulcers, to improve mobility and perhaps raise self-esteem. Besides local factors such as infection or necrosis, systemic factors such as patient's compliance, renal insufficiency and immunosuppression are of relevance and should be adequately taken care of. The effects of oral drug therapy for venous and arterial disease has been disappointing. ${ }^{14}$ Local dressings are important in ulcers, the choice of dressing depends on the nature of the ulcer and the tolerability of the dressing for the patient. ${ }^{14}$ Wound management requires repeated debridement and wet dressings. ${ }^{10}$ In the present study a variety of agents were used for the dressing of ulcer and more commonly several agents were used in a single patients hence an increase in their percentage. Povidone iodine and hydrogen peroxide were used in great majority of cases. All patients with chronic leg ulcer must be assessed for their vascular status. Almost all patients with ulcerated legs benefit from the use of compression bandaging at a level appropriate to their vascular status. In patients with venous ulcers, multi-layer bandaging appears to be the most cost effective means available. ${ }^{14}$

Culture and sensitivity showed that a larger number of ulcers were secondarily infected $(66 \%)$ A short course of broad spectrum antibiotics was administered initially to all patients and the agents and doses modified depending upon the culture and sensitivity report from the department of microbiology. 34\% of ulcers were noninfected probably because of the facts that the patients himself had applied varied antiseptics, antibiotics cream and herbal preparations. Non-healing ulcers can be caused by variety of infections including environmental organisms (if exposure to soil, hay or other plant materials). Chronic ulcers can become deep and extend to bone and allows bacteria to infect the bone. Besides illfitting shoes or casts or splints or spinal cord damage may also cause ulcers unless the pressure point is relieved, the wound will not heal. Skin ulcers can present as a nonhealing sometime ulcerated lesion and require early medical attention and that a delay in treatment will result in need for more extensive surgery. With regard to stay in hospital, majority in patients stayed in the hospital for about two weeks and the longest stay was of 6 weeks in cases of deep infected ulcers and following amputation. In $68 \%$ cases complete healing was materialized within 3 months. Though in 2 cases it took 9 months for complete healing. This probably appeared to be due to noncompliance in respect to follow up, not properly dressing the wound or due to repeated trauma. Sundresh et al. ${ }^{2}$ observed that most chronic leg ulcers were healed within 3 months in contrast to our observations requiring long duration of follow up and complete healing.

Ulcer healing is a multifactorial and complex process. Generally chronic wounds begin as acute wounds, it is still not known at what point the healing sequence is interrupted so that normal acute healing of wound fails to materialize. ${ }^{15,16}$ One of the first major processes in wound healing is inflammation, which is regulated by several pro-inflammatory cytokines, which are potent inducers of matrix-metalloproteinases (MMPs) synthesis. ${ }^{17,18}$ Among the proteases that have been consistently reported to be increased in chronic wounds are the MMPs, and that MMP activity is specifically inhibited by the tissue inhibitors of metalloproteinases (TIMPs). ${ }^{19-21}$ Lobmann et al. ${ }^{1}$ observed that the combination of increased concentration of MMPs (MMP-2, MMP-9, MMP-8) with decreased concentration of TIMP-2 in chronic diabetic foot ulcer compared with healing traumatic wound in non-diabetic patients suggest that the increased proteolytic environment contribute to the failure of diabetic wounds to heal. Compared to diabetic foot ulcers 
which cause considerable morbidity and mortality along with increased cost of management, non-diabetic chronic lower extremity ulcers cause lesser morbidity and negligible mortality. In our study in only 3 cases toes amputation was done leading to morbidity and prolonged stay at hospital but complete recovery was noted. Armstrong et al. ${ }^{11}$ noted that diabetics were 45 times more likely to have lower extremity amputation than nondiabetics, in their study of infected punctured wounds of the foot of diabetics and non-diabetics patients in line with our observations.

\section{CONCLUSION}

Chronic non-healing ulcers of lower extremity are fairly common and pose serious challenge to treating surgeon, burden to society in terms of cost and loss of working hours, apart from casting misery and anxiety to patient. Majority of patients are drawn from lower socioeconomic class, illiterate males using tobacco or alcohol. They require long-term regular follow up though studded with poor compliance (major concern). In non-diabetic patients, ulcers do cause morbidity but mortality is none. Old age, obesity altered lipid profile, atherosclerosis, consumption of alcohol and tobacco Absence of light touch, impaired pain perception, absent dorsalis pedis pulse were significant predictors of chronic lower extremity ulcers.

\section{ACKNOWLEDGEMENTS}

We would like to thank our patients who participated in this study. Also we are thankful to our colleagues and paramedical staff who helped and supported us throughout the study.

Funding: No funding sources

Conflict of interest: None declared

Ethical approval: The study was approved by the institutional ethics committee

\section{REFERENCES}

1. Lobmann R, Ambrosch A, Schultz G, Waldmann K, Schiweck S, Lehnert H. Expression of matrix metalloproteinases and their inhibitors in the wounds of diabetic and non-diabetic patients. Diabetologia. 2002;45:1011-6.

2. Sundresh NJ, Narendran S, Ramanathan M. Identifying specific etiology of non-diabetic chronic leg ulcers. Int J Pharmacother. 2012;2:48-50.

3. Strandness DE, Priest RE, Gibbons GE. Combined clinical and pathologic study of diabetic and nondiabetic peripheral arterial disease. Diabetes. 1964;13:366-72.

4. Tassiopoulos AK, Golts E, Oh DS, Labropoulos N. Current concepts in chronic venous ulceration. Eur J Vasc Endovasc Surg. 2000;20(3):227-32.
5. Ribu L, Hanestad BR, Moum T, Birkeland K, Rustoen T. A comparison of the health related quality of life in patients with diabetic foot ulcers, with a diabetes group and a non-diabetes group from the general population. Qual Life Res. 2007;16:17989.

6. Baker SR, Stacey MC, Jopp-Mckay AG, Hoskin SE, Thompson PJ. Epidemiology of chronic venous ulcers. Br J Surg. 1991;78:844-67.

7. Burton CS. Treatment of leg ulcers. Dermatol Clin. 1993;11:315-23.

8. Sethia KK, Darke SG. Long saphenous incompetence as a cause of venous ulceration. $\mathrm{Br} \mathrm{J}$ Surg. 1984;76:745-55.

9. Kowal-vern A, Criswell BK. Burn scar neoplasms: a literature review and statistical analysis. Burns. 2005;31(4):403-13.

10. Mechanick JI. Practical aspects of nutritional support for wound healing patients. Am J Surg. 2004;188(IA Suppl):52-6.

11. Armstrong DG, Lavery LA, Quebedeaux TL, Walker SC. Surgical morbidity and the risk of amputation due to infected puncture wounds in diabetic versus nondiabetic adults. J Am Pediatr Med Assoc. 1997;87:321-6.

12. Adam DJ, Naik J, Hartshorne T, Bello M, London NJ. The diagnosis and management of 689 chronic leg ulcers in a single-visit assessment clinic. Eur $\mathbf{J}$ Vasc Endovasc Surg. 2003;25(5):462-8.

13. Dean S. Leg ulcers - causes and management. Aust Fam Physician. 2006;35(7):480-4.

14. Goodfield M. Optimal management of chronic leg ulcers in the elderly. Drugs Aging. 1997;10(10):341-8.

15. 15. Falanga V. Chronic wounds: pathophysiologic and experimental considerations. J Invest Dermatol 1993; 100: 721-25.

16. Nwomch BC, Yager DR, Cohen IK. Physiology of the chronic wound. Clin Plast Surg. 1998;25:34156.

17. Bennett NT, Schultz GS. Growth factors and wound healing biochemical properties of growth factors and their receptors. Am J Surg. 1993;165:728-37.

18. Mauviel A. Cytokine regulation of metalloproteinase gene expression. J Cell Biochem. 1993;53:288-95.

19. Kähäri VM, Saarialho-Kere U. Matrix metalloproteinases in skin. Exp Dermatol. 1997;6:199-213.

20. Ravanti I, Kähäri VM. Matrix metalloproteinases in wound repair. Int J Mol Med. 2000;6:391-407.

21. Madlener M. Differential expression of matrix metalloproteinases and their physiologic inhibitors in acute murine skin wounds. Arch Dermatol Res. 1998;290:24-9.

Cite this article as: Mukherjee S, Raza MA, Mukherjee S, Bansal P, Joshi G. A prospective, open label, clinical study for evaluation of management of chronic nonhealing, non-diabetic leg ulcers in a tertiary care hospital. Int Surg J 2015;2:560-5. 